\title{
Development of a new clinical mastitis detection method for automatic milking systems
}

\author{
M. Khatun, ${ }^{*} \dagger^{1}$ P. C. Thomson, ${ }^{*}$ K. L. Kerrisk, ${ }^{*}$ N. A. Lyons, $\neq$ C. E. F. Clark, ${ }^{*}$ J. Molfino, ${ }^{*}$ and S. C. García* \\ *Dairy Science Group, Faculty of Science, Sydney Institute of Agriculture, School of Life and Environmental Sciences, The University of Sydney, \\ Camden 2570, New South Wales, Australia \\ †Bangladesh Agricultural University, Mymensingh 2202, Bangladesh \\ fIntensive Livestock Industries, New South Wales, Department of Primary Industries, Elizabeth Macarthur Agricultural Institute, Menangle 2568, \\ New South Wales, Australia
}

\section{ABSTRACT}

This study investigated the potential for accurate detection of clinical mastitis $(\mathrm{CM})$ in an automatic milking system (AMS) using electronic data from the support software. Data from cows were used to develop the model, which was then tested on 2 independent data sets, 1 with 311 cows (same farm but from a different year) and 1 with 568 cows (from a different farm). In addition, the model was used to test how well it could predict CM 1 to $3 \mathrm{~d}$ before actual clinical diagnosis. Logistic mixed models were used for the analysis. Twelve measurements were included in the initial model before a backward elimination, which resulted in the following 6 measurements being included in the final model: quarter-level milk yield (MY; $\mathrm{kg}$ ), electrical conductivity $(\mathrm{EC} ; \mathrm{mS} / \mathrm{cm})$, average milk flow rate $(\mathrm{MF} ; \mathrm{kg} / \mathrm{min})$, occurrence of incompletely milked quarters in each milking session (IM; yes or no), MY per hour $(\mathrm{MYH} ; \mathrm{kg} / \mathrm{h})$, and EC per hour $(\mathrm{ECH} ; \mathrm{mS} /$ $\mathrm{cm} / \mathrm{h}$ ) between successive milking sessions. The other 6 measurements tested but not included in the final model were peak milk flow rate $(\mathrm{kg} / \mathrm{min})$, kick-offs (yes or no) in each milking session, lactation number, days in milk (d), blood in milk (yes or no), and a calculated mastitis detection index used by DeLaval (DelPro software; DeLaval International AB, Tumba, Sweden). All measurements were assessed to determine their ability to detect $\mathrm{CM}$ as both individual variables and combinations of the 12 above-mentioned variables. These were assessed by producing a receiver operating characteristic curve and calculating the area under the curve (AUC) for each model. Overall, 9 measurements (i.e., EC, ECH, MY, MYH, MF, IM, peak flow rate, lactation number, and mastitis detection index) had significant mastitis detection ability as separate predictors. The

Received December 19, 2017.

Accepted June 4, 2018.

${ }^{1}$ Corresponding author: mkha3293@uni.sydney.edu.au best mastitis prediction was possible by incorporating 6 measurements (i.e., EC, ECH, MY, MYH, MF, and IM) as well as the random cow and quarter effects in the model, resulting in $90 \%$ sensitivity and $91 \%$ specificity with excellent AUC (0.96). Assessment of the model was found to produce robust results $($ AUC $>0.9$ ) in different data sets and could detect $\mathrm{CM}$ with reductions in sensitivity and specificity with increasing days before actual diagnosis. This study demonstrated that improved mastitis status prediction can be achieved by using multiple measurements, and new indexes based on that are expected to result in improved accuracy of mastitis alerts, thereby improving the detection ability and utility on farm.

Key words: dairy cow, clinical mastitis, automatic milking system, pasture-based

\section{INTRODUCTION}

Bovine mastitis is an inflammation of the udder or mammary gland that is typically caused by invading bacteria belonging predominantly to Enterobacteriaceae, Staphylococcaceae, or Streptococcaceae families (Bradley, 2002). Mastitis is commonly classified into subclinical, clinical, and chronic forms, all of which cause significant animal welfare concerns. The economic impact of clinical mastitis (CM) associated with production losses, treatment, and culling rate ranged from $\$ 36$ to $\$ 470 /$ cow per year, with large differences between farms (Halasa et al., 2007; Huijps et al., 2008; Lam et al., 2013). Interest in and adoption of automatic (robotic) milking systems (AMS) have created the demand for reliable automatic detection of mastitis due to the reduction in inspection time required to identify mastitic cows that need veterinary intervention (Mollenhorst et al., 2012). Many commercial brands supplying AMS already incorporate a variety of milk monitoring or sensing equipment (e.g., electrical conductivity, milk yield, milk flow rate, incomplete milking, kick-off), and some researchers have been working to develop algo- 
rithms that use and integrate data captured during the milking process to find the most accurate mastitis alert guideline (Hogeveen et al., 2010; Hovinen and Pyörälä, 2011; Rutten et al., 2013). Accuracy is determined by a high incidence of true-positive cases (high sensitivity; Se) and low incidence of false alerts (high specificity; Sp). Previous studies have shown that the use of only $\mathrm{EC}$ in different detection algorithms was unable to achieve the ISO (2007) standard Se $(>70 \%)$ and Sp (>99\%) for CM detection (Khatun et al., 2017). In the past decade, many attempts have been made to improve the Se and Sp of CM detection using AMS data; however, they were not successful enough to detect at quarter level, and the search for an improved automated mastitis detection system continues (Claycomb et al., 2009; Hogeveen et al., 2010; Penry et al., 2017). Moreover, in a pasture-based AMS, where cows are less visible to the farmers compared with an indoor farming system, checking multiple alerts (either automatic or nonautomatic) to improve Se and Sp for detection of mastitis requires an increase in workload (Steeneveld et al., 2010). Given that mastitis can be associated with multiple changes (Sordillo, 2005) in the cow's body and milk, it is possible that we could achieve higher Se and $\mathrm{Sp}$ if we integrate additional measurements captured during milking (e.g., milk yield, milking frequency, milk flow rate, milking pattern). Exploiting multisensor information could lead to sustainable improvements in detection of mastitis (Brandt et al., 2010; Hogeveen et al., 2010; Steeneveld et al., 2010). Thus, the objective of this study was to develop a multiple measurement approach or index for inline AMS sensors to detect CM targeting $>80 \%$ Se and $\geq 99 \%$ Sp.

\section{MATERIALS AND METHODS}

\section{Data Source}

A retrospective longitudinal cohort study was conducted with data collected from 2 pasture-based robotic dairy farms. Farm 1 was located near Camden, New South Wales, Australia $\left(34.0544^{\circ} \mathrm{S}, 150.6958^{\circ} \mathrm{E}\right.$; rainfall $=764 \mathrm{~mm} / \mathrm{yr}$ ) and belonged to the University of Sydney, and farm 2 was a commercial dairy farm located near Deloraine, Tasmania, Australia $\left(41.5349^{\circ} \mathrm{S}\right.$, $146.6616^{\circ} \mathrm{E}$; rainfall $=1,016 \mathrm{~mm} / \mathrm{yr}$ ). Farm 1 had 85 ha of effective grazing land for about 350 Holstein-Friesian lactating cows with daily access to annual ryegrass (Lolium multiflorum) oversown on kikuyu (Pennisetum clandestinum) and oats (Secale cereale) in autumn, winter, and spring. Animals were supplemented with approximately $7 \mathrm{~kg}$ DM of grain-based commercial pelleted concentrate ( $18 \%$ protein) per cow in the postmilking area (in automated out-of-parlor feeders) after each milking session and with a partial mixed ration containing primarily brewer's grain, orange pulp, and pasture silage to cover true pasture deficits. Cows were fitted with a neck-mounted electronic rumination and activity monitoring tag (SCR HR-LDn; SCR Engineers Ltd., Netanya, Israel). On farm 2, cows were offered a combination of grazable pasture (Lolium perenne), partial mixed ration, and grain-based commercial pelleted concentrate targeting daily DMI of $22.5 \mathrm{~kg}$ of DM/ cow. The percentage of each feed in the daily allocation varied depending on the availability of pasture. Cows had access to grain-based commercial pelleted concentrate (based on DIM) after milking in 20 automated out-of-parlor feeders (FSC400, DeLaval International AB, Tumba, Sweden) located in an area immediately postmilking. Both farms operated with voluntary cow traffic and a 3-way grazing system (Lyons et al., 2013b). The herds of both farms were predominately Holstein-Friesian with a year-round calving system in farm 1 and a split ( 2 batches) calving system in farm 2. In both farms, cows were milked through a robotic rotary system (DeLaval Automatic Milking Rotary, Tumba, Sweden; 24-unit platform, 5 robotic arms). All data were recorded and stored in the herd management software (DeLaval DelPro Software 5.1; DeLaval International $\mathrm{AB})$.

Nine measurements (variables) relating to the individual milking event for each cow (out of 81 measurements available in the software) were selected to identify the best CM predictors. These included milk yield (MY; kg/cow per milking), electrical conductivity $(\mathbf{E C} ; \mathrm{mS} / \mathrm{cm})$, incomplete milking (IM; yes or no), average milk flow rate (MF; $\mathrm{kg} / \mathrm{min})$, peak milk flow rate $(\mathbf{P F} ; \mathrm{kg} / \mathrm{min}$ ), kick-offs (yes or no), blood in milk (yes or no), lactation number, and DIM (d). In addition, the mastitis detection index (MDi; unitless) was included within the variables to be tested. This is an index generated within DelPro software that incorporates EC, blood in milk, and milking interval per quarter to give an indication of likelihood of mastitis. As MY (Ouweltjes, 1998) and EC (Fernando et al., 1981) are both affected by the milking interval, these 2 variables were divided by milking interval to estimate MY per hour (MYH; $\mathrm{kg} / \mathrm{h}$ ) and EC per hour $(\mathbf{E C H} ; \mathrm{mS} / \mathrm{cm}$ per hour). This resulted in a total of 12 variables to be included in the analysis.

\section{Gold Standard for CM and Control}

The quarters included in this study included both clinically infected and healthy quarters. In both farms the protocol used for the definition of $\mathrm{CM}$ was a record of veterinary treatment where the day of treatment was considered as d 0. Normal farm practice was to moni- 
tor DelPro EC records at least once daily to flag the suspected mastitis cases. Cows that were deemed by farm staff to have elevated EC in 1 or more quarters $(>7.5 \mathrm{mS} / \mathrm{cm}$, without a strict threshold) were drafted before the next milking to allow visual inspection of the suspect quarter (for redness, heat, and swelling) and its milk (for the presence of flakes, clots, or lumps). The CM-positive cases were determined by trained farm staff's assessment of clinical cases after potentially affected animals had been identified by changes in EC. Thus, although unlikely, it is possible that some true cases of CM could have gone unnoticed (false negatives). In addition, the cows recorded as incompletely milked (IM) or with abnormal rumination or activity (e.g., SCR HR-LDn sensor) were separated by the farm staff and checked for CM. The CM-positive cases were treated with antibiotics $[3$ doses of Special Formula 17900-Forte Suspension (Zoetis, Kirkland, QC, Canada) every $12 \mathrm{~h}$, and milk was discarded during this period. On farm 2, in addition to looking at EC, quarters with poor milk letdown, 2 consecutive IM or kick-offs, and MDi $>9$ were checked for signs of CM. The nontreated quarters of the CM-positive cows and 1,176 quarters of 294 milking cows without any record of CM during a 12-wk time window (chosen arbitrarily) were considered as the negative control.

\section{Data Distribution}

Three data sets were identified (2 data sets from farm 1 and 1 data set from farm 2), with cows having $\mathrm{CM}$ in a single quarter or multiple quarters or no CM (negative controls) in any quarter. An initial data set from farm 1 was used to develop the model. The model was then tested using a second data set (collected in a different time period) from farm 1 (assessment 1). The data set from farm 2 was used for further assessment of the model (assessment 2).

Data were selected from around 4 wk before CM treatment of the cow by extraction from DelPro. Due to the large data set of healthy cows, 2,000 data records were selected randomly using the "sample" function in $\mathrm{R}$ version 3.2.5 (http://www.r-project.org) to balance the data size of single-quarter and multiple-quarters $\mathrm{CM}$ data sets before analysis. In model selection, the proportion of single-quarter $\mathrm{CM}$ versus negative control versus multiple-quarter $\mathrm{CM}$ mastitis cow data was 1:2:3 $(1,078: 2,000: 3,116)$. The number of single-quarter CM and multiple-quarter CM cases and other selection criteria of the 3 data sets is presented in Table 1. Missing values ranged from 3 to $6 \%$, and any missing value or any single observation (predictor variable, 1.6-2.3\%) more than 4 SD (based on expected extreme deviation of the normally distributed sample size used in the analysis) from its mean was not included in the analysis.

\section{Statistical Analysis}

Model Selection. The 12 different AMS variables extracted from the AMS were considered as predictor variables to test their association with $\mathrm{CM}$. The data were analyzed using ASReml-R (Butler et al., 2007) built under $\mathrm{R}$ version 3.2.5 (http://www.r-project.org). Three sets of logistic generalized linear mixed models (GLMM) were constructed (univariable, multivariable,

Table 1. Selection criteria of data sets

\begin{tabular}{|c|c|c|c|}
\hline Item & $\begin{array}{c}\text { Model selection and implementation } \\
\text { Farm } 1\end{array}$ & $\begin{array}{l}\text { Assessment } 1 \\
\text { Farm } 1\end{array}$ & $\begin{array}{l}\text { Assessment } 2 \\
\quad \text { Farm } 2\end{array}$ \\
\hline \multicolumn{4}{|l|}{ Cows without mastitis } \\
\hline Records collected during study ${ }^{1}$ & 323 & 278 & 512 \\
\hline Cows with mastitis in multiple quarters & $40^{3}$ & $20^{3}$ & $10^{4}$ \\
\hline $\begin{array}{l}\text { Quarters with mastitis in multiple } \\
\text { quarters }\end{array}$ & 210 & 281 & 64 \\
\hline Total quarter milkings & 24,776 & 24,464 & 25,008 \\
\hline Lactation number & 1 to 9 & 1 to 9 & 1 to 7 \\
\hline DIM & 191 & 157 & 94 \\
\hline Data extraction period & October 2014 to March 2016 & April 2016 to September 2016 & July 2016 to December 2016 \\
\hline Missing value $(\%)$ & 3.4 & 6.0 & 3.01 \\
\hline \multicolumn{4}{|c|}{${ }^{1}$ Total number of healthy cow records collected during the study period. } \\
\hline \multicolumn{4}{|c|}{ 2Total number of cow records used in the analysis selected by the "sample" function in R (http://www.r-project.org/). } \\
\hline
\end{tabular}


and multivariable interaction) to find the best predictors of $\mathrm{CM}$ as a binary outcome. Initially, univariable logistic GLMM were fitted to each of the 12 variables as a fixed effect using the following model:

$$
\begin{gathered}
\ln [\pi /(1-\pi)]=\text { constant }+ \text { predictor } \\
+ \text { cow }+ \text { cow.quarter }
\end{gathered}
$$

where $\pi=P(Y=1)$ is the probability that the cow has $\mathrm{CM}$ in a particular quarter on a particular test session, predictor was one of the 12 variables listed above as a fixed effect, and cow and cow-quarter (quarter nested within a cow) were random effects. As the distribution of $\mathrm{MYH}, \mathrm{ECH}, \mathrm{MDi}, \mathrm{MF}$, and $\mathrm{PF}$ were positively skewed, they were log (base e)-transformed before fitting the logistic regression model to reduce leverage of very large values.

Following this, variables identified in the univariable analyses as having indicative associations $(P<0.2)$ were included in an initial multivariable model along with the same random effects as in the univariable models, and a manual backward elimination procedure was used to drop nonsignificant variables. Wald $\mathrm{F}$ and Wald chi-squared tests were used for significance testing, and the final model included any variables with $P<0.05$. The variable MDi was excluded from the multivariable model because it is a composite index including several variables (e.g., EC, blood in milk, milking interval) that were already in the model. The third stage of modeling included the evaluation of interactions between fixed effects. All possible 2-way interactions were evaluated between pairs of variables (categorical $\times$ categorical and categorical $\times$ quantitative). A backward elimination procedure was again used to eliminate nonsignificant interactions, and the cow- and quarter-specific information was used as random effects. The final multivariable model may be written as

$$
\ln [\pi /(1-\pi)]=\beta_{0}+\boldsymbol{\beta}^{\prime} \mathbf{x}+u_{C}+u_{C Q},
$$

where $\mathbf{x}=\left(x_{1}, x_{2}, \ldots, x_{p}\right)^{\prime}$ is the set of fixed effect predictor values (including interaction terms) with associated regression coefficients $\boldsymbol{\beta}$, and $u_{C}$ and $u_{C Q}$ are the random cow and cow-quarter effects.

Model Implementation on Farm 1. After selecting and fitting the final model, the estimates of the fixed effect $\hat{\boldsymbol{\beta}}$ (excluding the estimated constant or intercept) and the random effect estimates for each cow $\left(\hat{u}_{C}\right)$ and cow-quarter $\left(\hat{u}_{C Q}\right)$ were obtained, and an index (1 index value including each observation used in model selection in farm 1) was created on the linear predictor (LP; unitless) scale as below:
$\mathrm{LP}=\hat{\boldsymbol{\beta}}^{\prime} \mathbf{x}+\hat{u}_{C}+\hat{u}_{C Q}=\hat{\beta}_{1} x_{1}+\hat{\beta}_{2} x_{2}+\ldots+\hat{\beta}_{p} x_{p}+\hat{u}_{C}+\hat{u}_{C Q}$,

Increasing values of LP indicate greater probability of CM, and different thresholds of LP can be applied. When compared against the known case-control status, Se and Sp values can be determined at each threshold $L P$ value. Note that the estimated intercept $\hat{\boldsymbol{\beta}}_{0}$ was not included in the LP value because its value would change according to the sampling fraction of control cowquarters and its value does not influence Se and $\mathrm{Sp}$ calculations. Receiver operating characteristic (ROC) curves were used to visually present the Se and Sp using different threshold values.

ROC Curve. The ROC curve is a plot of Se (truepositive rate; $\mathrm{y}$-axis) versus 1 - Sp (false-positive rate; $\mathrm{x}$-axis) and is a graphical illustration of the diagnostic value of the test (Hanley and McNeil, 1982). The curve is traced out by applying varying thresholds to an index (LP), and the area under the curve (AUC) was used as an overall measure of diagnostic test performance, classified as excellent (0.9-1), good (0.8-0.9), fair (0.7-0.8), poor (0.6-0.7), and fail (0.5-0.6; http:// gim.unmc.edu/dxtests/roc3.htm), with values under 0.5 worse than random classification. The construction of the ROC curves was performed using the AUC package (version 0.3.0) in $\mathrm{R}$ (version 3.2.4; https://www.r -project.org/). Among the ranges of LP values in the constructed ROC curve, the optimum cut-off value for the final multivariable model was defined as a threshold point where the sum of Se and Sp was maximum; a value exceeding the cut-off is a CM indicator. Each predictor variable that was significant as a univariable model was also assessed independently by AUC values based on observed records of AMS values and LP values obtained from the univariable GLMM including the cow $\left(\hat{u}_{C}\right)$ and quarter-specific $\left(\hat{u}_{C Q}\right)$ information as random effects at the optimum cut-off value. A similar evaluation was performed for the final multivariable model.

Model Assessments 1 and 2. In this analysis, the fitted model from farm 1 was applied to a separate set of data recorded in different time periods on the same farm (assessment 1) as well as to a new data set belonging to farm 2 (assessment 2). This was undertaken in 2 ways. First, an LP value was calculated for each observation in each data set using the fixed effect estimates from the model selection stage without any random effects included-for example, $\mathrm{LP}=\hat{\boldsymbol{\beta}}^{\prime} \mathbf{x}=\hat{\beta}_{1} x_{1}+\hat{\beta}_{2} x_{2}+\ldots+\hat{\beta}_{p} x_{p}$. Following that, the AUC value of the LP value and Se and Sp at the optimum cut-off were evaluated as described previously. Such a model without inclusion of random effects is 
appropriate in situations where no prior information is available for a cow or its 4 quarters. Second, when previous mastitis history (previous mastitis records within the same or previous 2 lactations) is available for the cow and quarter, this information in the form of estimates $\hat{u}_{C}$ and $\hat{u}_{C Q}$ can still be included in the LP calculation by initially fitting a model as follows:

$$
\ln [\pi /(1-\pi)]=\hat{\boldsymbol{\beta}}^{\prime} \mathbf{x}+\beta_{0}+u_{C}+u_{C Q},
$$

where $\hat{\boldsymbol{\beta}}^{\prime} \mathbf{x}$ is specified as an offset using the estimates $\hat{\boldsymbol{\beta}}$ from model selection in farm 1 as fixed constants, and $\mathbf{x}=\left(x_{1}, x_{2}, \ldots, x_{p}\right)^{\prime}$ is the set of fixed effect predictor values in model assessment data sets (assessments 1 and 2). The estimates of the random effects $\hat{u}_{C}$ and $\hat{u}_{C Q}$ were calculated for the model assessment data sets (second data set of farm 1 and data set of farm 2). Next, the LP was calculated for each observation, including the previous mastitis history of cow $\left(\hat{u}_{C}\right)$ and quarter $\left(\hat{u}_{C Q}\right)$ information, as in model implementation in farm 1 (e.g., $\left.\mathrm{LP}=\hat{\boldsymbol{\beta}}^{\prime} \mathbf{x}+\hat{u}_{C}+\hat{u}_{C Q}\right)$.

Model Assessment at Earlier Days Prior to CM Diagnosis. In this step, the final model was assessed using the same data set as the development model selection in the first data set of farm 1 and the data set of farm 2 to determine the utility of the model predicting CM before actual diagnosis. Using the fitted model from farm 1, the test was evaluated assuming that $\mathrm{CM}$ was present only on the day of diagnosis $(\mathrm{d} 0)$ up to $1 \mathrm{~d}$ (prior d 1), up to $2 \mathrm{~d}$ (prior d 2), and up to 3 $\mathrm{d}$ (prior d 3) before diagnosis. Evaluations were also made to assess test Se on each specific prior day. During assessment at prior days, we used the same estimates $\hat{\boldsymbol{\beta}}$ from model selection in farm 1 following the same procedure as mentioned above in the assessment steps. $\mathrm{R}$ code was written to prepare the data set to set the CM status as positive for the specified prior day. The LP calculated for the models with and without the random effect were compared for AUC as well as Se at the optimum cut-off of $\mathrm{d} 0$.

\section{RESULTS}

\section{Model Selection and Implementation (Univariable Models)}

The significance level of the 12 predictor variables to predict CM with the cow $\left(\hat{\sigma}_{C}^{2}\right)$ and quarter $\left(\hat{\sigma}_{C Q}^{2}\right)$ variance estimates is presented in Table 2 . In general, out of the 12 predictor variables, 9 of these (EC, ECH, MY, MYH, MDi, IM, MF, PF, and lactation number) had associations $(P<0.05)$ with $\mathrm{CM}$ status in the univari-
Table 2. Significance of the 12 predictor variables to predict clinical mastitis with the cow and quarter variance by univariable GLMM ${ }^{1}$

\begin{tabular}{lccc}
\hline Variable $^{2}$ & $P$-value & Cow $\left(\sigma^{2}\right)^{3}$ & Quarter $\left(\sigma^{2}\right)^{3}$ \\
\hline $\mathrm{EC}$ & $<0.001$ & $0.27 \pm 0.13$ & $0.24 \pm 0.14$ \\
$\mathrm{ECH}^{4}$ & $<0.001$ & $0.21 \pm 0.14$ & $0.68 \pm 0.18$ \\
$\mathrm{MY}$ & $<0.001$ & $0.34 \pm 0.16$ & $0.67 \pm 0.19$ \\
$\mathrm{MYH}^{4}$ & $<0.001$ & $0.21 \pm 0.15$ & $0.71 \pm 0.19$ \\
$\mathrm{MF}^{4}$ & $<0.001$ & $0.31 \pm 0.16$ & $0.71 \pm 0.20$ \\
$\mathrm{IM}$ & $<0.001$ & $0.23 \pm 0.15$ & $0.77 \pm 0.20$ \\
$\mathrm{PF}^{4}$ & $<0.001$ & $0.38 \pm 0.17$ & $0.69 \pm 0.19$ \\
$\mathrm{MDi}^{4}$ & $<0.001$ & $0.14 \pm 0.13$ & $0.61 \pm 0.18$ \\
Lactation number & 0.002 & $0.22 \pm 0.15$ & $0.67 \pm 0.19$ \\
DIM & 0.15 & $0.36 \pm 0.17$ & $0.64 \pm 0.18$ \\
Blood in milk & 0.43 & $0.32 \pm 0.16$ & $0.63 \pm 0.18$ \\
Kick-offs & 0.39 & $0.32 \pm 0.16$ & $0.64 \pm 0.18$ \\
\hline
\end{tabular}

${ }^{1}$ Logistic generalized linear mixed models included variables with estimated fixed effects.

${ }^{2} \mathrm{EC}=$ electrical conductivity $(\mathrm{mS} / \mathrm{cm}) ; \mathrm{ECH}=$ electrical conductivity per hour $(\mathrm{mS} / \mathrm{cm}$ per hour); $\mathrm{MY}=$ milk yield $(\mathrm{kg}) ; \mathrm{MYH}=$ milk yield per hour $(\mathrm{kg} / \mathrm{h}) ; \mathrm{MF}=$ average milk flow rate $(\mathrm{kg} / \mathrm{min}) ; \mathrm{IM}=$ incomplete milking in each milking session (yes/no); $\mathrm{PF}=$ peak milk flow rate $(\mathrm{kg} / \mathrm{min}) ; \mathrm{MDi}=$ mastitis detection index.

${ }^{3} \sigma^{2}=$ variance estimate \pm SE.

${ }^{4}$ Because of positively skewed distribution, data were log-transformed. ${ }^{*} P<0.05 ;{ }^{* * *} P<0.001$.

able GLMM analyses, and 1 additional variable (DIM) had a weak $(P=0.15)$ association worth considering in the initial multivariable model. The other 2 (kick-offs and blood in milk) were nonsignificant $(P>0.2)$ in the univariable GLMM and therefore not included in the initial multivariable model. The CM prediction ability of each of the 9 univariable models $(P<0.05)$ based on visual measurement from AMS (observed record) were poor compared with GLMM with random effect at LP scale based on the AUC values (Table 3). Among the univariable models, the best-performing univariable model was MYH based on observed record $(\mathrm{AUC}=$ $0.859)$ as well as at LP scale $(\mathrm{AUC}=0.940)$, which takes into account prior history of $\mathrm{CM}$ in each cow and cow-quarter by inclusion of random effects.

\section{Model Selection and Implementation (Multivariable Models)}

After backward elimination, the final multivariable model included 6 variables (all $P<0.001$ ). The 6 variables were EC, ECH, MY, MYH, MF, and IM. The nonsignificant variables were $\mathrm{PF}$, lactation number, and DIM. Pairwise interactions were considered between variables (all $P>0.05$ ). The estimated regression coefficients, $\hat{\boldsymbol{\beta}} \pm \mathrm{SE}(\hat{\boldsymbol{\beta}})$, of the 6 predictor variables of the final model were EC $(1.30 \pm 0.095), \mathrm{ECH}(-2.11$ $\pm 0.341), \mathrm{MY}(-0.875 \pm 0.179), \mathrm{MYH}(1.34 \pm 0.333)$, MF $(-1.75 \pm 0.264)$, and IM $(1.30 \pm 0.187)$. These regression coefficients were used as fixed values in the 
model implementation (farm 1) and assessments (assessment 1 and assessment 2) to calculate the LP value, only cow and quarter random effects were estimated to reflect the history (previous mastitis information within the same or previous 2 lactations) of cow and quarter records. The estimated optimum LP cut-off of the final model based on the maximum sum of Se and Sp was $>8.24$ for the model with random effects and $>7.84$ for the model without random effects. These 2 cut-off values were used as reference values for all other assessments and compared with optimum cut-offs for other assessments (e.g., cutoffs to maximize $\mathrm{Se}+\mathrm{Sp}$ for each specific model assessment). The CM prediction ability of the final model on the LP scale was excellent (AUC $=0.96$ vs. 0.92 ) for the model with and without random effects, respectively. At the optimum cut-off, the calculated Se (90\% vs. $84 \%$ ) and Sp (91\% vs. 88\%) were better for the model with random effects than without random effects, respectively (Table 4). Overall, the performances of the final multivariable model containing 6 predictors were better (in terms of both AUC and the maximum sum of Se and Sp) than any of the 9 univariable predictors. This was true regardless of whether random effects were included in the model.

\section{Model Assessments 1 and 2 (Multivariable Models)}

Assessment 1 (using the second data set of farm 1) and assessment 2 (using the data set of farm 2) values of the final model were robust and had excellent AUC $(>0.9)$ value for the models with and without random effects. The variation in ROC curves for the model with and without random effects at the model implementation, assessment 1, and assessment 2 steps is presented in Figures 1 and 2, respectively. The optimum cut-off in assessment 1 (>7.80 vs. $>7.25$ ) and assessment 2 $(>6.52$ vs. $>5.80)$ for the models with and without random effects differ from the optimum cut-offs (e.g., reference values) of model implementation (>8.24 vs. $>7.84$ ). Comparing the Se between model implementation versus assessment 1 and model implementation versus assessment 2 for the model with random effects only at the corresponding optimum cut-off, there was $5 \%$ higher Se in assessment 1 (cut-off: $>8.24$ vs. $>7.80$ ) and $27 \%$ higher Se in assessment 2 (cut-off: $>8.24$ vs. $>6.52$ ). Similarly, such Se comparison between model implementation versus assessment 1 and model implementation versus assessment 2 for the model without random effects only at the corresponding optimum

Table 3. Analysis of receiver operating characteristic curves, sensitivity, and specificity at optimum cut-off value for prediction of clinical mastitis based on observed automatic milking system records and by univariable GLMM $^{1}$ at linear predictor scale $(\mathrm{n}=358 \text { cows })^{2}$

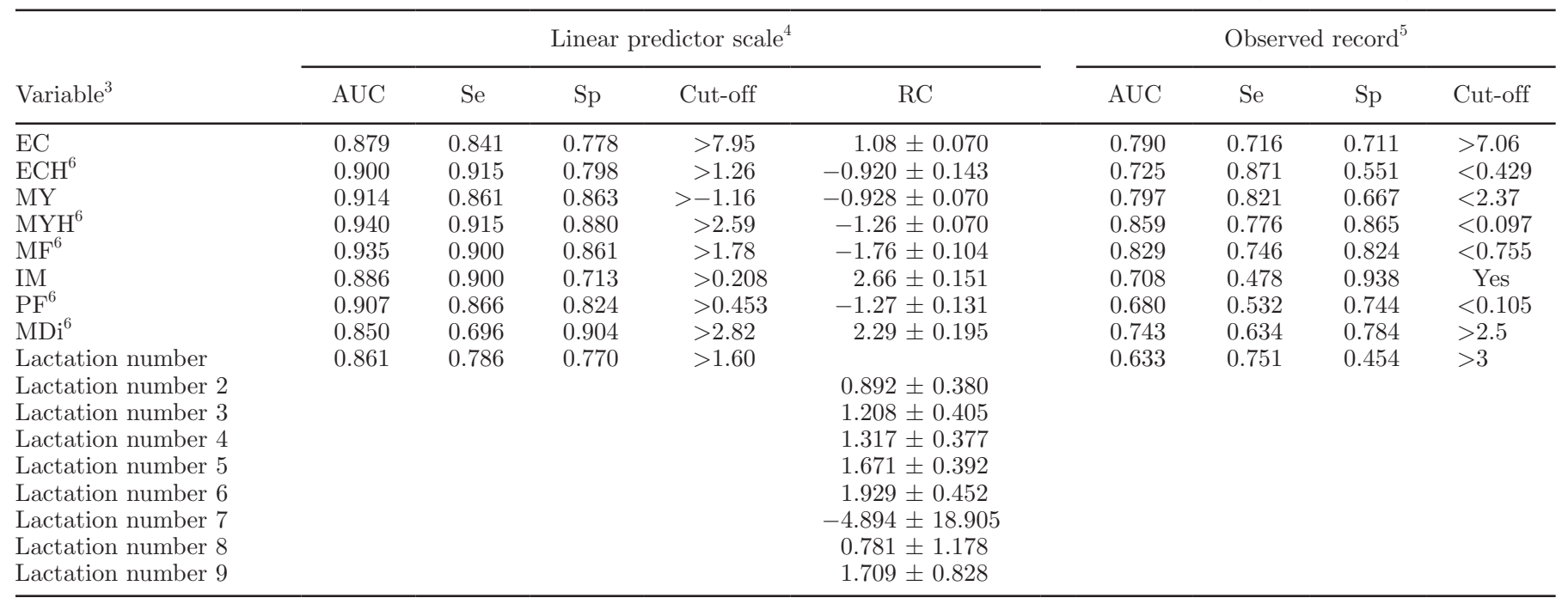

${ }^{1}$ Logistic generalized linear mixed models included variables with estimated fixed effects.

${ }^{2} \mathrm{AUC}=$ area under the curve; $\mathrm{Se}=$ sensitivity; $\mathrm{Sp}=$ specificity; Cut-off = threshold point where sum of sensitivity and specificity is maximum; a value exceeding the cut-off is a mastitis indicator; $\mathrm{RC}=$ regression coefficient $\pm \mathrm{SE}$.

${ }^{3} \mathrm{EC}=$ electrical conductivity $(\mathrm{mS} / \mathrm{cm}) ; \mathrm{ECH}=$ electrical conductivity per hour ( $\mathrm{mS} / \mathrm{cm}$ per hour); $\mathrm{MY}=$ milk yield $(\mathrm{kg}) ; \mathrm{MYH}=$ milk yield per hour $(\mathrm{kg} / \mathrm{h}) ; \mathrm{MF}=$ average milk flow rate $(\mathrm{kg} / \mathrm{min}) ; \mathrm{IM}=$ incomplete milking in each milking session (yes $/$ no); $\mathrm{PF}=$ peak milk flow rate $(\mathrm{kg} / \mathrm{min}) ; \mathrm{MDi}=$ mastitis detection index.

${ }^{4} \mathrm{An}$ index value including estimated fixed effects (excludes the estimated intercept) and the random effect estimates for each cow and cowquarter.

${ }^{5}$ Receiver operating characteristic curve generated from visual record from automatic milking system.

${ }^{6}$ Because of positively skewed distribution, data were log-transformed before calculating linear predictor. 
cut-off, the Se was always higher $(10 \%$ to $27 \%)$ in assessments (cut-offs: $>7.25$ in assessment $1,>5.80$ in assessment 2) compared with implementation (cut-off: $>7.84$ ). In such comparisons, the Sp was 3 to $5 \%$ lower in assessment data sets compared with that obtained in the model implementation. When comparing the Se and $\mathrm{Sp}$ at the corresponding optimum cut-off of assessments 1 and 2, the values were higher for the model with random effects than the model without random effects as presented in Table 4. In addition, comparing the Se at the specific cut-off of $>8.24$ for the model with and without random effects, we obtained $20 \%$ (assessment 1: $85 \%$ vs. $65 \%$ ) to $23 \%$ (assessment 2: $66.7 \%$ vs. $43.3 \%$ ) higher Se due to inclusion of random effects. The equivalent comparison for Sp showed 2 to $6 \%$ higher Sp (in the models with or without random effects) at the corresponding optimum cut-off than the cut-off of $>8.24$.

\section{Model Assessments at Earlier Days Prior to CM Diagnosis (Multivariable Model)}

Model assessment values for multiple consecutive prior days $\mathrm{CM}$ at the farm-specific optimum cut-off (farm 1: $>8.24$ vs. $>7.84$; farm 2 : $>6.52$ vs. $>5.80$ ) for the model with and without random effects are presented in Table 5. In general, better AUC values with higher Se and Sp were found for the model with random effects than the model without random effects in both farms.
In farm 1, the AUC values of the model decreased gradually (0.96 to 0.93 vs. 0.92 to 0.81 ) due to increasing number of prior days as $\mathrm{CM}$ in the model with and without random effects. For the model with random effects, the Se and Sp were always higher on d 0; Se decreased gradually from $90 \%$ to $85 \%$, and Sp decreased from $91 \%$ to $83 \%$ with increasing number of prior days as $\mathrm{CM}$ in the model. For the model without random effects, Se also decreased from $83 \%$ to $54 \%$ with minor variation in $\mathrm{Sp}$.

In farm 2, except d 0 to prior d 1 (model with random effect), the AUC and Se were always higher on d 0 compared with other times. There was minor variation in Sp in both models with and without random effects.

In the evaluation on each specific prior day at the same cut-off as mentioned above, Se decreased sharply in farm 1 (90\% to $37 \%$ vs. $84 \%$ to $34 \%$ ) and in farm 2 (93\% to $13 \%$ vs. $80 \%$ to $29 \%$ ) for the model with and without random effects, respectively. Similar to previous assessments, Se was higher for the model with random effects compared with the model without random effects.

\section{DISCUSSION}

This study endeavored to predict CM by analyzing and integrating multiple inline sensor data with robust assessment values in 2 pasture-based farms. We developed and tested a multivariable linear predictor index (LP) capable of detecting CM at quarter level,

Table 4. Analysis of receiver operating characteristic curves, sensitivity, and specificity at different cut-off values for prediction of clinical mastitis by multivariable GLMM $^{1}$ at linear predictor scale ${ }^{2}$

\begin{tabular}{|c|c|c|c|c|c|c|c|c|c|c|c|c|}
\hline \multirow{3}{*}{$\begin{array}{l}\text { Item }^{3} \\
\text { AUC } \\
\text { Cut-off }\end{array}$} & \multicolumn{5}{|c|}{ With random effects ${ }^{4}$} & \multicolumn{7}{|c|}{ Without random effects ${ }^{4}$} \\
\hline & \multirow{2}{*}{$\begin{array}{r}\mathrm{MI}^{5} \\
0.958 \\
>8.24^{8}\end{array}$} & \multicolumn{2}{|c|}{ Assessment $1^{6}$} & \multicolumn{2}{|c|}{ Assessment $2^{7}$} & \multirow{2}{*}{$\frac{\mathrm{MI}}{0.921}$} & \multicolumn{3}{|c|}{ Assessment $1^{6}$} & \multicolumn{3}{|c|}{ Assessment $2^{7}$} \\
\hline & & 0.9 & & 0.9 & & & & 0.910 & & & 0.912 & \\
\hline $\mathrm{Se}$ & 0.900 & 0.850 & 0.897 & 0.667 & 0.933 & 0.836 & 0.762 & 0.864 & 0.650 & 0.533 & 0.8 & 0.433 \\
\hline Sp & 0.906 & 0.900 & 0.872 & 0.996 & 0.972 & 0.884 & 0.899 & 0.846 & 0.928 & 0.994 & 0.927 & 0.996 \\
\hline
\end{tabular}

${ }^{1}$ Logistic generalized linear mixed models included variables with estimated fixed effects (regression coefficient $\pm \mathrm{SE}$ ): electrical conductivity, $1.30 \pm 0.095$; log-transformed electrical conductivity per hour, $-2.11 \pm 0.341$; milk yield, $-0.875 \pm 0.179$; log-transformed milk yield per hour, $1.34 \pm 0.333$; log-transformed mean milk flow rate, $-1.75 \pm 0.264$; and incomplete milking, $1.30 \pm 0.187$.

${ }^{2}$ An index value including estimated fixed effects (excludes the estimated constant or intercept) and the random effect estimates for each cow and cow-quarter.

${ }^{3} \mathrm{AUC}=$ area under the curve; Se = sensitivity; $\mathrm{Sp}=$ specificity; Cut-off = threshold point where sum of sensitivity and specificity is maximum; a value exceeding the cut-off is a mastitis indicator.

${ }^{4}$ Random effect $=$ cow- and quarter-specific information, including previous mastitis history.

${ }^{5}$ Model implementation using the first data set of farm 1 ( $\mathrm{n}=358$ cows).

${ }^{6}$ Assessment 1 using the second data set of farm 1 ( $\mathrm{n}=311$ cows $)$.

${ }^{7}$ Assessment 2 using the data set of farm 2 ( $\mathrm{n}=568$ cows).

${ }^{8}$ Optimum cut-off as evaluated in farm 1 with random effect (model implementation).

${ }^{9}$ Farm- and data set-specific optimum cut-off with random effect.

${ }^{10}$ Optimum cut-off as evaluated in farm 1 without random effect (model implementation).

${ }^{11}$ Farm- and data set-specific optimum cut-off without random effect. 
With random effect

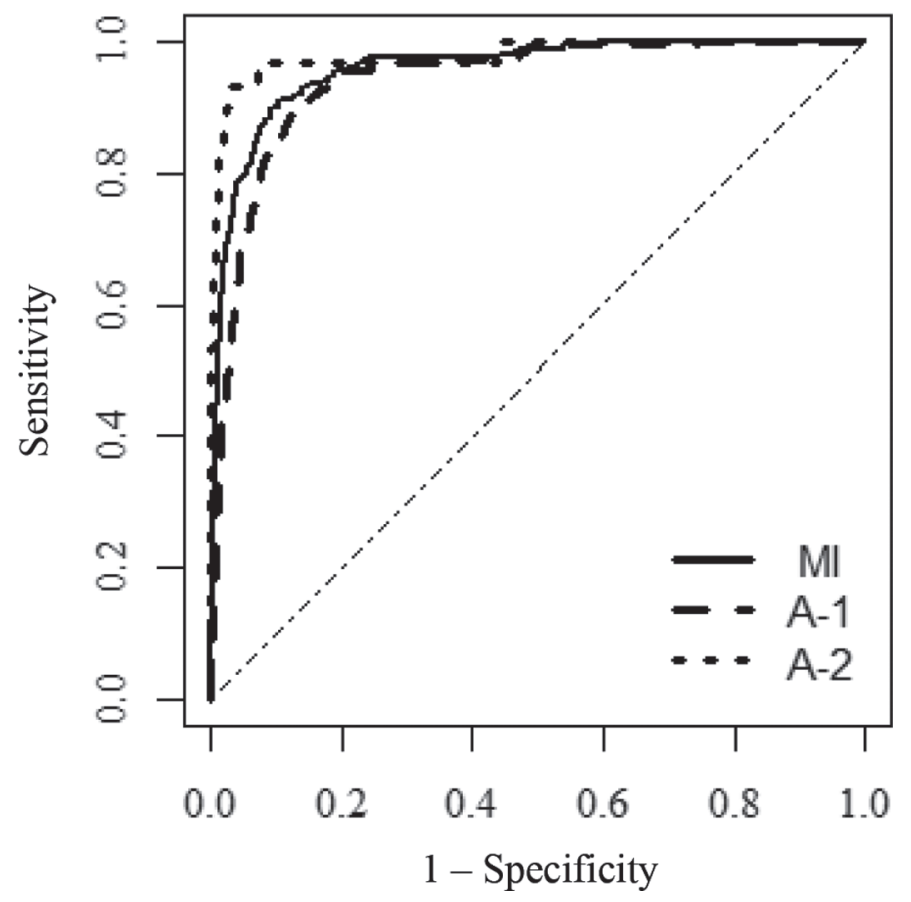

Figure 1. Receiver operating characteristic curves of multivariable logistic generalized linear mixed models at implementation (MI) and assessment steps in farm 1 (A-1: assessment 1) and farm 2 (A-2: assessment 2). Random effects included cow and quarter nested within cow. Models included variables with estimated fixed effects (regression coefficient $\pm \mathrm{SE}$ ): electrical conductivity, $1.30 \pm 0.095$; log-transformed electrical conductivity per hour, $-2.11 \pm 0.341$; milk yield, $-0.875 \pm$ 0.179 ; log-transformed milk yield per hour, $1.34 \pm 0.333$; log-transformed mean milk flow rate, $-1.75 \pm 0.264$; and incomplete milking, $1.30 \pm 0.187$.

which to the best of our knowledge has better Se and Sp than any existing single inline sensor. We evaluated our models using ROC curves, which have also been used successfully for monitoring other diseases (e.g., hyperketonemia) and radiologic imaging diagnostics (Hanley and McNeil, 1982; van der Drift et al., 2012; Perkins et al., 2013).

The excellent AUC value of the final multivariable LP index with higher balance Se and Sp than any of the univariable LP index further supports the idea that better mastitis detection is possible by integrating multiple types of information and measurements rather than using single variable measurements (Brandt et al., 2010; Hogeveen et al., 2010; Steeneveld et al., 2010). If solely relying on AMS measurements, it is difficult to identify the CM cases early enough because milk fractions might influence sensor results (Sarikaya and Bruckmaier, 2006). Thus, in this study, we aimed to develop a multivariable index to maximize the Se and Sp by integrating multiple sources of sensor informa-
Without random effect

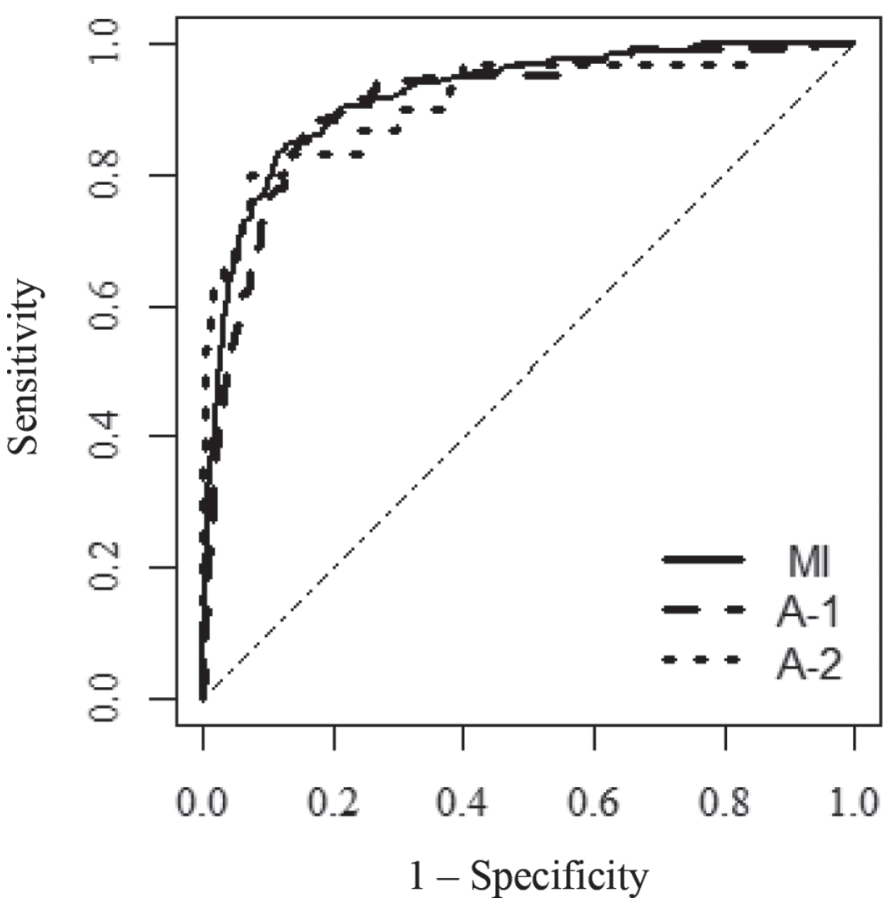

Figure 2. Receiver operating characteristic curves of multivariable logistic generalized linear mixed models at implementation (MI) and assessment steps in farm 1 (A-1: assessment 1) and farm 2 (A-2: assessment 2). Models included variables with estimated fixed effects (regression coefficient $\pm \mathrm{SE}$ ): electrical conductivity, $1.30 \pm 0.095$; log-transformed electrical conductivity per hour, $-2.11 \pm 0.341$; milk yield, $-0.875 \pm 0.179$; log-transformed milk yield per hour, $1.34 \pm$ 0.333 ; log-transformed mean milk flow rate, $-1.75 \pm 0.264$; and incomplete milking, $1.30 \pm 0.187$. These models do not include any cow and quarter nested within cow as random effect.

tion that are available in all the different brands of AMS commercially available. As a baseline, we compared with ISO standard Se $(>70 \%)$ and Sp $(\geq 99 \%)$ recommended for automatic discarding of abnormal milk (Mein and Rasmussen, 2008; Sherlock et al., 2008). It should be noted that our multivariable model index can also achieve the ISO standard at a higher cut-off of the index than mentioned in the text, but we argue that the cost for missing the true-positive cases might compensate for missing the true negative cases. That is why we aimed for the maximum sum of Se and Sp as the farm- and data-specific optimum cut-off. The limitation at this optimum cut-off was that our index leaves $9 \%$ of cows as wrongly classified as having CM (e.g., up to 36 false alerts in a herd of about 400 cows; farm 1). However, this level of error may be acceptable for a pasture-based AMS compared with other more labor-demanding approaches as mentioned by Steeneveld et al. (2010). However, further optimization might be possible by incorporating cows' immune 
Table 5. Comparison of the area under the curve, sensitivity, and specificity at optimum cut-off assuming clinical mastitis for different prior days by multivariable GLMM $^{1}$ at linear predictor scale ${ }^{2}$

\begin{tabular}{|c|c|c|c|c|c|c|c|c|}
\hline Time $^{3}$ & \multicolumn{4}{|c|}{ With random effects ${ }^{4}$} & \multicolumn{4}{|c|}{ Without random effects ${ }^{4}$} \\
\hline D 0 & 0.958 & 0.900 & 0.906 & \multirow[t]{4}{*}{$>8.24^{6}$} & 0.921 & 0.836 & 0.884 & \multirow[t]{4}{*}{$>7.84^{7}$} \\
\hline D 0 to prior d 1 & 0.947 & 0.858 & 0.890 & & 0.886 & 0.708 & 0.887 & \\
\hline D 0 to prior d 2 & 0.936 & 0.834 & 0.870 & & 0.852 & 0.613 & 0.890 & \\
\hline D 0 to prior d 3 & 0.927 & 0.850 & 0.839 & & 0.813 & 0.543 & 0.892 & \\
\hline \multicolumn{9}{|l|}{ Farm $2^{8}$} \\
\hline D 0 to prior d 1 & 0.982 & 0.956 & 0.934 & \multirow{3}{*}{$>6.52^{9}$} & 0.761 & 0.556 & 0.924 & \multirow{3}{*}{$>5.80^{10}$} \\
\hline D 0 to prior d 2 & 0.736 & 0.305 & 0.979 & & 0.704 & 0.481 & 0.924 & \\
\hline D 0 to prior d 3 & 0.711 & 0.249 & 0.978 & & 0.669 & 0.424 & 0.925 & \\
\hline
\end{tabular}

${ }^{1}$ Logistic generalized linear mixed models included variables with estimated fixed effects (regression coefficient \pm SE): electrical conductivity, $1.30 \pm 0.095$; log-transformed electrical conductivity per hour, $-2.11 \pm 0.341$; milk yield, $-0.875 \pm 0.179$; log-transformed milk yield per hour, $1.34 \pm 0.333$; log-transformed mean milk flow rate, $-1.75 \pm 0.264$; and incomplete milking, $1.30 \pm 0.187$.

${ }^{2}$ An index value including estimated fixed effects (excludes the estimated constant or intercept) and the random effect estimates for each cow and cow-quarter.

${ }^{3} \mathrm{D} 0=$ actual day of clinical mastitis diagnosis; prior day = prior single day of actual mastitis treatment; the corresponding number in column 1 indicates the number of prior days endorsed as pseudomastitis.

${ }^{4}$ Random effect $=$ cow- and quarter-specific information, including previous mastitis history. AUC = area under the curve; Se = sensitivity; Sp $=$ specificity; Cut-off $=$ threshold point where sum of sensitivity and specificity is maximum; a value exceeding the cut-off is a mastitis indicator.

${ }^{5}$ Assessment for prior days using the first data set of farm $1(\mathrm{n}=358$ cows).

${ }^{6}$ Optimum cut-off as evaluated on d 0 with random effect in farm 1.

${ }^{7}$ Optimum cut-off as evaluated on d 0 without random effect in farm 1.

${ }^{8}$ Assessment for prior days using the data set of farm $2(\mathrm{n}=568$ cows).

${ }^{9}$ Optimum cut-off as evaluated on d 0 with random effect in farm 2.

${ }^{10}$ Optimum cut-off as evaluated on d 0 without random effect in farm 2.

information (DeLaval lactate dehydrogenase or others). Another encouraging outcome of our study was the 20 to $23 \%$ increase in Se at a fixed cut-off $(>8.24)$ due to inclusion of previous CM history of the cow (random effects) in the assessment data sets. This reflects the statistical prediction ability of biological relevance with repeated cases without knowing any causal factors (Abureema et al., 2014). However, to account for such random effects in on-farm situations, we need to ensure that there is enough information about previous lactations, or previous days of the current lactation, before creating ROC curves; otherwise, Se may decline markedly. We noticed much lower Se in assessment 2 $(66.7 \%)$ than in assessment $1(85 \%)$ at the same cut-off $(>8.24)$ due to absence of cow-level and quarter-level mastitis history (Table 1). However, such variation can also be due to different farm conditions with different sample sizes. Despite variation, such an approach of inclusion of information to account for random effects for milking-related information might be more useful when combined with other test procedures such as SCC and lactate dehydrogenase (Chagunda et al., 2006; Kamphuis et al., 2008; Sørensen et al., 2016). Moreover, in such evaluation, we might consider cow- or quarterspecific optimum cut-off as we noticed higher sum of Se and Sp at the farm- and data-specific cut-off in both as- sessment $1($ sum $=1.769$ vs. 1.75 ; cut-off $=7.8$ vs. 8.24$)$ and assessment 2 (sum $=1.905$ vs. 1.663 ; cut-off: 6.52 vs. 8.24) with random effect or without random effect (assessment 1 : sum $=1.71$ vs. 1.661 , cut-off $=7.25$ vs. 7.84 ; assessment 2 : sum $=1.727$ vs. 1.527 , cut-off $=5.8$ vs. 7.84). The procedure did show ability to detect CM on days before actual diagnosis. However, the ability to do this reliably declined, with reductions in Se and Sp with increasing days before actual diagnosis showing the ability to monitor false-positive and false-negative cases.

Moreover, our collective study findings also support the observations from previous studies with single or limited information. For example, MYH, the best single inline measurement, has been previously found to be useful for detection of nonspecific health problems (Lukas et al., 2009). Moreover, a previous study reported by our research group found that MYH has a nonlinear association with the milking interval, with reduced $\mathrm{MYH}$ when the milking interval is more than $16 \mathrm{~h}$ (Lyons et al., 2013a). As milking interval is not controlled in pasture-based AMS, MYH might not be a better CM predictor in such situations despite the high AUC (0.94) obtained in our study. Our study also suggests that EC alone is not powerful enough for CM prediction even using different statistical algorithms (Kamphuis et al., 
2008; Khatun et al., 2017). This might be explained by the effect of temperature, fat content, or milk fraction on EC measurements (Nielen et al., 1992; Bruckmaier et al., 2004). The decreasing trend $(<0.429 \mathrm{mS} / \mathrm{cm}$ per hour, opposite to EC) of the ECH for the CM alert might be related to milking interval as mastitic cows are prone to have longer milking intervals, allowing longer harboring of the pathogens causing infection (Hogeveen et al., 2001; Hammer et al., 2012; Penry et al., 2017). Similar to a recent report by another group, our study did not find strong CM prediction ability of $\mathrm{PF}$, which is considered an important breeding parameter (Penry et al., 2017). The correlation of the parameters included in the final model ranged from -0.32 to 0.71 , and $\mathrm{PF}$ was moderately correlated with $\mathrm{MF}(\mathrm{r}=0.76)$, but using the backward elimination procedure it was not included in the final multivariable model. Although many farmers use MDi for routinely checking for mastitis, MDi did not perform better than EC even though this index incorporates multiple measurements such as EC, MF, and blood in milk. The reasons behind the poor performance of MDi might be due to the effect of blood in milk or milk color as influenced by milk fat color and breed (Rasmussen and Bjerring, 2005). Compared with MDi, a better AUC value of IM was achieved with higher Se and Sp at the optimum cut-off (LP scale), and this was supported by the use of direct visual observations in farm 2, where $50 \%$ of mastitis cases were detected twice based on an IM alert before MDi indicated an alert (personal communication with N. Dornauf, farm owner, Gala Farm, Tasmania).

Another important aspect of our index is that it might be a cost effective and understandable approach for farmers (as the value is absolute) for automatic detection of cows at risk for $\mathrm{CM}$ with low false alerts, especially in a pasture-based system with minimal farmer-cow contact. In this way, it will reduce labor requirements and costs associated with visual inspection of cows. It is possible that even more accurate levels of CM prediction could be obtained if immune and behavioral variables were incorporated; this will be the focus of further investigations.

\section{CONCLUSIONS}

We developed and evaluated a multivariable quarterlevel CM prediction index in AMS. Overall, our study found that better CM prediction is possible by using multiple automatically recorded inline sensor data records rather than a single sensor data record. The best-fitting model used information on EC, ECH, MY, $\mathrm{MYH}, \mathrm{MF}$, and IM. Incorporation of cow and quarter previous mastitis history (random effects) improved the performance of the test procedures. The present model is suited for estimation of the quarter-, cow-, and herdlevel mastitis alarm and expected to result in improved accuracy of mastitis alerts, thereby improving the detection ability and practicality on farm.

\section{ACKNOWLEDGMENTS}

The authors thank Gerrit Koop (Utrecht University, Utrecht, the Netherlands) for his contributions and ideas on the utilization of different sources of AMS information by statistical modeling to predict mastitis. The authors also thank two former $\mathrm{PhD}$ students of the University of Sydney (Alex John, Ashleigh Wildridge), and Kim McKean (former farm manager of the University of Sydney) for their assistance in collecting the data. This project was supported by FutureDairy (Camden, NSW, Australia) and the Dairy Research Foundation of The University of Sydney (Australia). The first author is the recipient of an Australian Endeavour PhD Scholarship.

\section{REFERENCES}

Abureema, S., P. Smooker, J. Malmo, and M. Deighton. 2014. Molecular epidemiology of recurrent clinical mastitis due to Streptococcus uberis: Evidence of both an environmental source and recurring infection with the same strain. J. Dairy Sci. 97:285-290. https:// doi.org/10.3168/jds.2013-7074.

Bradley, A. 2002. Bovine mastitis: An evolving disease. Vet. J. 164:116-128. https://doi.org/10.1053/tvjl.2002.0724.

Brandt, M., A. Haeussermann, and E. Hartung. 2010. Invited review: Technical solutions for analysis of milk constituents and abnormal milk. J. Dairy Sci. 93:427-436. https://doi.org/10.3168/jds.2009 -2565 .

Bruckmaier, R. M., D. Weiss, M. Wiedemann, S. Schmitz, and G. Wendl. 2004. Changes of physicochemical indicators during mastitis and the effects of milk ejection on their sensitivity. J. Dairy Res. 71:316-321. https://doi.org/10.1017/S0022029904000366.

Butler, D., B. Cullis, A. Gilmour, and B. Gogel. 2007. ASReml-R Reference Manual. Dept Prim. Ind. Fish., Brisbane, Australia.

Chagunda, M. G. G., N. C. Friggens, M. D. Rasmussen, and T. Larsen. 2006. A model for detection of individual cow mastitis based on an indicator measured in milk. J. Dairy Sci. 89:2980-2998. https:// doi.org/10.3168/jds.S0022-0302(06)72571-1.

Claycomb, R. W., P. T. Johnstone, G. A. Mein, and R. A. Sherlock. 2009. An automated in-line clinical mastitis detection system using measurement of conductivity from foremilk of individual udder quarters. N. Z. Vet. J. 57:208-214. https://doi.org/10.1080/ 00480169.2009.36903.

Fernando, R. S., R. B. Rindsig, and S. L. Spahr. 1981. Effect of length of milking interval and fat content on milk conductivity and its use for detecting mastitis. J. Dairy Sci. 64:678-682. https://doi.org/10 .3168/jds.S0022-0302(81)82629-X.

Halasa, T., K. Huijps, O. Østerås, and H. Hogeveen. 2007. Economic effects of bovine mastitis and mastitis management: A review. Vet. Q. 29:18-31. https://doi.org/10.1080/01652176.2007.9695224.

Hammer, J. F., J. M. Morton, and K. L. Kerrisk. 2012. Quarter-milking-, quarter-, udder- and lactation-level risk factors and indicators for clinical mastitis during lactation in pasture-fed dairy cows managed in an automatic milking system. Aust. Vet. J. 90:167174. https://doi.org/10.1111/j.1751-0813.2012.00917.x.

Hanley, J. A., and B. J. McNeil. 1982. The meaning and use of the area under a receiver operating characteristic (ROC) curve. Radiology 143:29-36. https://doi.org/10.1148/radiology.143.1.7063747. 
Hogeveen, H., C. Kamphuis, W. Steeneveld, and H. Mollenhorst. 2010. Sensors and clinical mastitis - The quest for the perfect alert. Sensors (Basel) 10:7991-8009. https://doi.org/10.3390/s100907991.

Hogeveen, H., W. Ouweltjes, C. J. A. M. De Koning, and K. Stelwagen. 2001. Milking interval, milk production and milk flow-rate in an automatic milking system. Livest. Prod. Sci. 72:157-167.

Hovinen, M., and S. Pyörälä. 2011. Invited review: Udder health of dairy cows in automatic milking. J. Dairy Sci. 94:547-562. https:/ /doi.org/10.3168/jds.2010-3556.

Huijps, K., T. J. Lam, and H. Hogeveen. 2008. Costs of mastitis: Facts and perception. J. Dairy Res. 75:113-120. https://doi.org/ 10.1017/S0022029907002932.

ISO (International Organization for Standardization). 2007. ISO/DIS 20966: Automatic milking installations - Requirements and testing. ISO, Geneva, Switzerland.

Kamphuis, C., R. Sherlock, J. Jago, G. Mein, and H. Hogeveen. 2008. Automatic detection of clinical mastitis is improved by in-line monitoring of somatic cell count. J. Dairy Sci. 91:4560-4570. https: //doi.org/10.3168/jds.2008-1160.

Khatun, M., C. E. F. Clark, N. A. Lyons, P. C. Thomson, K. L. Kerrisk, and S. C. García. 2017. Early detection of clinical mastitis from electrical conductivity data in an automatic milking system. Anim. Prod. Sci. 57:1226-1232. https://doi.org/10.1071/AN16707.

Lam, T. J. G. M., B. H. P. van den Borne, J. Jansen, K. Huijps, J. C. L. van Veersen, G. van Schaik, and H. Hogeveen. 2013. Improving bovine udder health: A national mastitis control program in the Netherlands. J. Dairy Sci. 96:1301-1311. https://doi.org/10.3168/ jds.2012-5958.

Lukas, J. M., J. K. Reneau, R. Wallace, D. Hawkins, and C. MunozZanzi. 2009. A novel method of analyzing daily milk production and electrical conductivity to predict disease onset. J. Dairy Sci. 92:5964-5976. https://doi.org/10.3168/jds.2009-2066.

Lyons, N. A., K. L. Kerrisk, N. K. Dhand, and S. C. Garcia. 2013a. Factors associated with extended milking intervals in a pasturebased automatic milking system. Livest. Sci. 158:179-188. https:/ /doi.org/10.1016/j.livsci.2013.10.010.

Lyons, N. A., K. L. Kerrisk, and S. C. Garcia. 2013b. Comparison of 2 systems of pasture allocation on milking intervals and total daily milk yield of dairy cows in a pasture-based automatic milking system. J. Dairy Sci. 96:4494-4504. https://doi.org/10.3168/ jds.2013-6716

Mein, G. A., and M. D. Rasmussen. 2008, Performance evaluation of systems for automated monitoring of udder health: Would the real gold standard please stand up? Pages 259-266 in Mastitis Control: From Science to Practice. T. J. G. M. Lam, ed. Wageningen Academic Publishers, Wageningen, the Netherlands.

Mollenhorst, H., L. J. Rijkaart, and H. Hogeveen. 2012. Mastitis alert preferences of farmers milking with automatic milking systems. J. Dairy Sci. 95:2523-2530. https://doi.org/10.3168/jds.2011-4993.
Nielen, M., H. Deluyker, Y. H. Schukken, and A. Brand. 1992. Electrical conductivity of milk: Measurement, modifiers, and meta analysis of mastitis detection performance. J. Dairy Sci. 75:606-614. https://doi.org/10.3168/jds.S0022-0302(92)77798-4.

Ouweltjes, W. 1998. The relationship between milk yield and milking interval in dairy cows. Livest. Prod. Sci. 56:193-201. https://doi .org/10.1016/S0301-6226(98)00154-7.

Penry, J. F., P. M. Crump, P. L. Ruegg, and D. J. Reinemann. 2017. Short communication: Cow-and quarter-level milking indicators and their associations with clinical mastitis in an automatic milking system. J. Dairy Sci. 100:9267-9272. https://doi.org/10.3168/ jds.2017-12839.

Perkins, N. J., E. F. Schisterman, and A. Vexler. 2013. Multivariate normally distributed biomarkers subject to limits of detection and receiver operating characteristic curve inference. Acad. Radiol. 20:838-846. https://doi.org/10.1016/j.acra.2013.04.001.

Rasmussen, M. D., and M. Bjerring. 2005. Visual scoring of milk mixed with blood. J. Dairy Res. 72:257-263. https://doi.org/10 .1017/S0022029905000853.

Rutten, C. J., A. G. J. Velthuis, W. Steeneveld, and H. Hogeveen. 2013. Invited review: Sensors to support health management on dairy farms. J. Dairy Sci. 96:1928-1952. https://doi.org/10.3168/ jds.2012-6107.

Sarikaya, H., and R. M. Bruckmaier. 2006. Importance of the sampled milk fraction for the prediction of total quarter somatic cell count. J. Dairy Sci. 89:4246-4250.

Sherlock, R., H. Hogeveen, G. Mein, and M. D. Rasmussen. 2008. Performance evaluation of systems for automated monitoring of udder health: Analytical issues and guidelines. Pages 275-282 in Mastitis Control: From Science to Practice. T. J. G. M. Lam, ed. Wageningen Academic Publishers, Wageningen, the Netherlands.

Sordillo, L. M. 2005. Factors affecting mammary gland immunity and mastitis susceptibility. Livest. Prod. Sci. 98:89-99. https://doi .org/10.1016/j.livprodsci.2005.10.017.

Sørensen, L. P., M. Bjerring, and P. Løvendahl. 2016. Monitoring individual cow udder health in automated milking systems using online somatic cell counts. J. Dairy Sci. 99:608-620. https://doi .org/10.3168/jds.2014-8823.

Steeneveld, W., L. C. van der Gaag, W. Ouweltjes, H. Mollenhorst, and H. Hogeveen. 2010. Discriminating between true-positive and false-positive clinical mastitis alerts from automatic milking systems. J. Dairy Sci. 93:2559-2568. https://doi.org/10.3168/jds .2009-3020.

van der Drift, S. G. A., R. Jorritsma, J. T. Schonewille, H. M. Knijn, and J. A. Stegeman. 2012. Routine detection of hyperketonemia in dairy cows using Fourier transform infrared spectroscopy analysis of $\beta$-hydroxybutyrate and acetone in milk in combination with test-day information. J. Dairy Sci. 95:4886-4898. https://doi.org/ 10.3168/jds.2011-4417. 